\title{
A NEUTRALIZAÇÃO DA ATUAL DOGMÁTICA JURÍDICA NO TOCANTE A RESOLUÇÃO DE QUESTÕES COMPLEXAS COMO A SUSTENTABILIDADE
}

\author{
Aline Cordeiro dos Santos* \\ Rosana Pereira Passarelli**
}

RESUMO: O presente artigo analisa a evolução histórica sociedade globalizada e as consequências dela advindas. Apresenta discussão acerca da expressão sustentabilidade e a natureza multidimensional do tema. Propõe a aproximação dos temas jurisdição e sustentabilidade. Destaca a necessidade da visão ampliada e coordenada do Direito, como instrumento de conexão e interpretação para a aplicabilidade coesa da jurisdição juntamente com a necessária aplicação do princípio da sustentabilidade.

Palavras-chave: Sustentabilidade; Globalização; Meio Ambiente; Jurisdição.

\section{THE NEUTRALISATION OF THE CURRENT LEGAL DOGMATIC REGARDING THE RESOLUTION OF COMPLEX ISSUES SUCH AS SUSTAINABILITY}

\begin{abstract}
This article analyses the historical evolution of the global society and the consequences of it. It presents discussion about the expression sustainability and the multidimensional nature of the theme. Proposes the approximation of the themes jurisdiction and sustainability. Highlights the need for the expanded and coordinated vision of the law, as an instrument of connection and interpretation for the cohesive applicability of the jurisdiction together with the necessary application of the principle of sustainability
\end{abstract}

Key words: Sustainability; Globalization; Envoronmental; Jurisdiction.

\footnotetext{
* Mestre em Direito. Pós Graduada em Direito do Trabalho e Processo do Trabalho. Graduada em Direito. Atuou como Coordenadora da Coordenadoria de Direito do Trabalho da Comissão do Jovem Advogado da OAB/SP. Foi Assistente de Coordenação em Cursos de Pós Graduação. Advogada Trabalhista atuante. Professora Universitária. Palestrante. Autora. E-mail: santosetorresadvogados@yahoo.com.br.

*** Mestre em Direito, linha de pesquisa: Empresa, Sustentabilidade e Funcionalização do Direito - UNINOVE. Especialista em Direito Empresarial e Direito Civil. Especialista em Meio Ambiente, Tecnóloga em Processos Gerenciais. Professora Universidade Nove de Julho, Advogada, Consultora Compliance Empresarial. E-mail: rosana.pereira@hotmail.com.
} 


\section{INTRODUÇÃO}

O desenvolvimento global proveniente do sistema capitalista impôs aos homens, o inevitável e real cenário de destruição ambiental.

A crise do capitalismo e das instituições político-jurídicas do mundo moderno constitui um novo paradoxo, um momento de transição pragmática que pode se caracterizar por um novo paradigma axiológico, ou seja, a sustentabilidade, como resposta a consciência humana quanto aos riscos advindos da chamada sociedade global.

Contudo, a utilização relativamente generalizada da expressão "sustentabilidade" revela o desconhecimento acerca do tema.

A bem da verdade, o tema está frequentemente relacionado às questões ambientais, principalmente, no que diz respeito à preservação dos recursos naturais como maneira de manter um equilíbrio apropriado no sentido puramente ecológico.

$\mathrm{Na}$ realidade, o significado da expressão sustentabilidade é mais abrangente, constituindo a questão ambiental apenas um de seus alicerces.

Neste sentido, a sustentabilidade não representa uma construção unidimensional e isolada. Ela apresenta uma natureza multidimensional, pois está intimamente interligada não somente a aspectos ambientais como também a aspectos éticos, jurídico-políticos, sociais e econômicos.

Desta maneira, urge que no cenário mundial atual, a sustentabilidade não pode ser compreendida única e tão somente como um simples adjetivo ou qualificativo de luxo que é incorporado a certas expressões ou propósitos discursivos, mas deve ser inserida como um projeto estratégico de sobrevivência futura sedimentada na consciência crítica dos indivíduos acerca da finitude dos recursos naturais e de sua responsabilidade pela proteção e melhora das condições de vida da sociedade.

Os efeitos da globalização impuseram implicações consideráveis acerca das multidimensões das sustentabilidade, o que acentua a complexidade da sociedade global e institui novas demandas no âmbito jurídico em vigor com a aproximação dos temas jurisdição e sustentabilidade.

Surge então a necessidade de novas respostas jurídicas dada a "judicialização" das relações sociais, especialmente quando a complexidade da relação entre o homem e o meio ambiente se impõe no cenário social. 
A realidade complexa e os conflitos surgidos na sociedade contemporânea requerem uma visão e atenção especial, havendo a necessidade de uma análise jurídica interligada e coordenada com disciplinas conexas.

Dessa forma, o presente trabalho busca mostrar a evolução e crescimento econômico vivenciado pela sociedade global impostos pelo sistema capitalista e as consequências do desenvolvimento frenético e desordenado ocasionado pelo fenômeno da globalização, bem como a própria crise do sistema capitalista e das instituições político-jurídicas do mundo contemporâneo.

A partir dessas premissas, este artigo passa a analisar a expressão sustentabilidade, que por sua vez, constitui o moderno paradoxo de transição pragmática que surge como resposta à sociedade de risco, fruto do modelo de produção e consumo industrial sedimentado na maximização do lucro e no desenvolvimento a qualquer custo.

Analisa a natureza multidimensional da sustentabilidade, apresentando a aproximação dos temas jurisdição e sustentabilidade, destacando a necessidade do ordenamento que, por sua vez, deve ser analisado como uma unidade complexa de comunicação normativa e que assegure a efetividade de todas as dimensões da sustentabilidade, ressaltando a necessidade da visão ampliada e coordenada do Direito, a fim de que, os segmentos jurídicos possam ser percebidos como instrumentos de conexão e interpretação para a realização coerente da jurisdição na pacificação dos conflitos advindos com os casos concretos postulados perante o Poder Judiciário.

Para a construção deste artigo, será empregado o método dedutivo, procurando partir de premissas gerais para chegar a uma conclusão específica sobre os temas por ora enfrentados. O tipo de pesquisa é o bibliográfico, pautado na análise da legislação, doutrina e dados disponíveis do tema posto em discussão.

\section{O PROBLEMA DA SUSTENTABILIDADE: UMA INVESTIGAÇÃO HISTÓRICA}

O rompimento dos valores e das crenças basilares da sociedade e da economia mundial desde a segunda metade do século XX até os dias atuais demonstra que a velocidade das transformações tem constituído a principal característica do mundo contemporâneo, ao mesmo passo em que aponta a incapacidade humana para a compreensão integral da realidade. 
Com o término do regime socialista, marcado pela queda do muro de Berlim (1989), surge o neoliberalismo que rapidamente contagiou o mundo. A mudança econômica fomentou a corrida pela competitividade, o implemento de novas tecnologias, a renovação das formas existentes de organização da produção e trabalho; contudo, ao mesmo tempo em que esta transformação proporcionou boas mudanças, trouxe consigo também o desemprego, a diminuição da renda e consequentemente o aumento das desigualdades já existentes na sociedade.

A globalização e a mundialização da produção, fez aumentar a parcela dos incluídos no consumo de massa (Extremo Oriente e Sudeste Asiático) com hábitos importados do Ocidente, bem como o crescimento do número de excluídos do mercado de trabalho em escala até então nunca vista.

A globalização da economia originada nos anos de 1980, nos Estados Unidos da América, fomentou a busca da competitividade e o crescimento da disputa por mercados, implementando novos paradigmas de negócios apoiados em inovações tecnológicas, na gestão de pessoas e no gerenciamento do conhecimento; diferenciais competitivos capazes de agregar valor aos negócios e colocar, rapidamente, à disposição dos clientes os melhores serviços.

Dentro deste contexto, o capitalismo manteve-se presente com a visão do ciclo produtivo, no qual é possível retirar do meio ambiente natural, todos os necessários insumos para a produção e, em seguida descartar os resíduos e poluentes, propiciando a poluição e a escassez dos recursos naturais de forma indiscriminada.

Como bem observa SACHS (1994, p.29), o rápido crescimento econômico não conseguiu estender um desenvolvimento completo em todos os domínios da atividade humana.

Na prática o que se observou foi um desenvolvimento predador e perverso, pois como assevera Roberto Pereira Guimarães, não é a riqueza (crescimento econômico) em si fator decisivo ao bem estar coletivo, e sim o uso que uma coletividade faz dela (GUIMARAES, 1997. p. 16).

Ao longo da história, os seres humanos, travam diariamente uma relação cada vez mais predatória com a natureza diante do modelo capitalista de produção, o que inevitavelmente torna real o cenário de desastre ambiental.

O fato é que do liberalismo ao neoliberalismo econômico, a continuidade da relação predatória homem-natureza é crescente. 
A crise do capitalismo e das instituições político-jurídicas do mundo moderno constitui um novo paradoxo, um novo momento de transição pragmática, que pode se caracterizar através da implementação de um novo paradigma axiológico, ou seja, a sustentabilidade, como resposta a consciência humana dos riscos advindos da chamada sociedade global.

A chamada sociedade global, também conhecida por sociedade de risco é fruto do modelo de produção e consumo industrial sedimentado na maximização do lucro e no desenvolvimento a qualquer custo.

O modelo de constituição desta sociedade é responsável pelo esgotamento dos recursos naturais não renováveis, pela ausência de uma distribuição equitativa dos bens naturais, pelo crescimento demasiado da população e multiplicação da pobreza, bem como dos novos processos tecnológicos excludentes fomentados pelo sistema capitalista.

Portanto, atualmente a convivência com situações de risco será algo muito comum no futuro da humanidade.

A instauração da crise ambiental, social e econômica, pela qual passa o capitalismo, tem evidenciado a consciência política coletiva, ganhando espaço no cenário mundial ampliando as discussões acerca da destruição do meio ambiente nos âmbitos público nacional e internacional.

Com o intuito de proteger e regulamentar em âmbito nacional e internacional as questões ambientais, tanto os Estados como a sociedade e as organizações internacionais, principalmente a ONU, por meio do Programa das Nações Unidas para o Meio Ambiente (PNUMA) e do Programa das Nações Unidas para o Desenvolvimento (PNUD), tem realizado uma série de conferências internacionais que marcam o início da autodefesa da sociedade, frente aos males que podem afetar a sua sobrevivência.

Cronologicamente, verifica-se como primeiro impulso político a publicação, em 1987, do informe da Comissão Mundial sobre o Meio Ambiente e Desenvolvimento, denominado Informe Brundtland: Nosso Futuro Comum, que introduziu e preconizou nas pautas da ONU o paradigma do desenvolvimento sustentável, ensejando a necessidade de satisfazer às necessidades básicas de todos, estendendo a sua preocupação para a chamada preocupação intergeracional.

A gênese do Direito Ambiental internacional marca um novo paradigma para a sociedade moderna; qual seja: o de estabelecer limites ao crescimento. 


\section{A SUSTENTABILIDADE E SUA NATUREZA MULTIDIMENSIONAL}

Atualmente sustentabilidade é um assunto muito comentado, porém pouco conhecido na realidade e em sua própria essência. Nesse contexto, o adjetivo "sustentável", conforme apresenta VEIGA (2005, p.188), tornou-se banalizado, pois busca qualificar um crescimento econômico permanente e afirmar uma possibilidade "de crescer sem destruir".

A bem da verdade, o tema está, frequentemente, relacionado às questões ambientais, principalmente no que diz respeito à preservação dos recursos naturais como maneira de manter um equilíbrio apropriado no sentido puramente ecológico.

Na realidade, o significado de sustentabilidade é muito mais abrangente, constituindo a questão ambiental apenas um de seus alicerces.

Neste sentido, como preleciona Juarez Freitas a sustentabilidade é multidimensional pressupondo que suas dimensões devam "ser tratadas em sincronia, com a transparência, e o atraso de uma dimensão acarreta forçosamente o atraso das demais" (FREITAS, 2012, p.86)

As dimensões da sustentabilidade estão interligadas, existe uma conexão intima que as mantem e assim devem ser vistas e aplicadas; as dimensões ética, jurídico-política, ambiental, social e econômica não podem ser rompidas e não apenas se tratam de características aleatórias, esparsas, mas sim de dimensões vinculadas umas às outras e essenciais como condicionantes do desenvolvimento. (FREITAS, 2012, p.91)

Nesta esteira de raciocínio, o termo sustentabilidade passará a ser analisado de acordo com as dimensões por ora mencionadas.

Na dimensão econômica da sustentabilidade o aspecto econômico tem necessidade de uma reformulação de comportamento haja vista que todos os bens necessários à satisfação das necessidades dos seres vivos são produzidos com recursos naturais escassos ou tendentes à escassez, assim, existe a premente necessidade de consciência de preservação do meio ambiente no sentido da utilização racional e equilibrada na exploração dos recursos da natureza.

Diante disso, surge a necessidade do combate ao desperdício, sendo indispensável a aplicação de medidas adequadamente capazes de estabelecer limites entre custos e benefícios.

E, novamente, nos dizeres de Juarez Freitas, "a sustentabilidade gera uma nova economia, com a reformulação de categorias e comportamentos, com o foco no planejamento a longo prazo e na eficiência" (FREITAS, 2012, p.66). 
Desta maneira, numa perspectiva estritamente econômica pode-se dizer que a sustentabilidade é a busca pelo equilíbrio entre a utilização dos recursos naturais e a produção de riqueza.

Sob a ótica da sociologia, conforme destaca o sociólogo Henrique Leff, o princípio da sustentabilidade surge como um critério normativo para a reconstrução da ordem econômica, como uma condição para a sobrevivência humana e um suporte para a conquista de um desenvolvimento duradouro, questionando as próprias bases da produção (LEF, 2005, p.31).

Invocando novamente Juarez de Freitas, temos como posicionamento a visão de uma economia sustentável, sustentada em progressos atuais da economia, sedimentada por estes, equilibrando custos e benefícios, diretos e indiretos, preocupação voltada ao combate dos desperdícios e regulamentação dos mercados para um eficácia, não bastando atingir a eficiência (FREITAS, 2012, p.60).

Portanto, o aspecto econômico da sustentabilidade não pode ser analisado como um fim em si, com o desprezo das situações de iniquidade social em nome da preservação dos modelos econômicos impostos pela sociedade de mercado e, da mesma forma que não pode ser analisado somente pelo viés da exploração.

Deste modo, para que os objetivos democráticos não configurem somente meras previsões constitucionais, a Constituição Brasileira de 1988 tratou expressamente no título VII, da Ordem Econômica e Financeira, dispondo em seu artigo 170, acerca dos princípios gerais norteadores da atividade econômica, entre os quais estabelecem respectivamente os incisos VI e VII a necessidade quanto à defesa do meio ambiente, inclusive diante de tratamento diferenciado conforme o impacto ambiental dos produtos e serviços e de seus processos de elaboração e prestação e, ainda, expresso pelo inciso VII, a necessidade tangente quanto à redução das desigualdades regionais.

Assim, percebe-se que o desenvolvimento econômico pressupõe tanto a defesa e a preservação do meio ambiente natural como também a promoção dos direitos sociais de modo a concretizar o objetivo fundamental de erradicar a pobreza e diminuir as desigualdades sociais e regionais.

No âmbito jurídico-político inicialmente observa-se que a sustentabilidade relacionase às decisões tomadas pelos governantes.

Talvez a melhor forma de traduzir a relevância da sustentabilidade política seja tratar das políticas públicas, cuja finalidade de implementação alicerça-se na garantia da qualidade 
do meio ambiente e constituem maneira de como o Poder Público se manifesta à população no âmbito interno de determinado Estado.

Para que as políticas públicas tenham o alcance almejado, devem surgir iniciativas que inibam ou proíbam o retrocesso de leis já estabelecidas.

Devem ser criados graus de proteção para garantias já alcançadas através das normas vigentes, de modo que o legislador não possa dispor livremente sobre os direitos fundamentais já estabelecidos em lei.

A lei protege e busca preservar um ambiente saudável e sustentável, por isso, não pode regredir trazendo velhos problemas à tona. Para a consecução deste objetivo, necessária se faz a garantia da sujeição às leis estabelecidas para todos os níveis da sociedade, independente de interesses particulares existentes.

Pretende-se deste modo, o estabelecimento de um mecanismo jurídico que não apenas preserve o meio ambiente no qual os seres vivos estão inseridos, mas também garanta a manutenção e o respeito às normas de caráter de direitos fundamentais já atingidas pela sociedade.

Assim como a Constituição da República Federativa do Brasil prevê em seu artigo 225:

Art. 225. Todos têm direito ao meio ambiente ecologicamente equilibrado, bem de uso comum do povo e essencial à sadia qualidade de vida, impondo-se ao Poder Público e à coletividade o dever de defendê-lo e preservá-lo para as presentes e futuras gerações.

Incluindo o Direito Ambiental como categoria de direito fundamental, a legislação poderá atingir de forma mais clara e contundente a preservação da vida digna em sociedade com um ambiente equilibrado.

Um dos objetivos mais relevantes para qualquer projeto de futuro sustentável é a constante busca pela melhora das condições sociais vivenciadas pelos indivíduos dentro da sociedade, afinal os problemas sociais estão intimamente inter-relacionados com os problemas ambientais, sendo somente possível a tutela do meio ambiente com a melhoria das condições da sociedade ${ }^{2}$. (SEM, 2000, p.10)

\footnotetext{
2 Para Amartya Sem o desenvolvimento real e pleno somente será alcançado com a expansão das liberdades, "desenvolvimento consiste na eliminação das privações de liberdade que limitam as escolhas e as oportunidades das pessoas de exercer ponderadamente sua condição de agente [...] assim, com oportunidades sociais adequadas, os indivíduos podem efetivamente moldar seu próprio destino e ajudar uns aos outros". (SEM, Amartya. Desenvolvimento como liberdade. São Paulo, São Paulo: Companhia das Letras, 2000, p.10, p.26).
} 
Neste compasso, alerta Boaventura de Souza Santos, quando afirma que a crise ambiental origina-se diretamente da transnacionalização da pobreza, da miséria e da fome (SANTOS, 2001, p. 42).

Desta maneira, é por meio da atuação jurisdicional e do efetivo controle das políticas públicas, necessária se faz a justiça social, afim de que haja uma distribuição equitativa tanto dos benefícios, quanto dos riscos produzidos pelo desenvolvimento. Dentro deste contexto a dimensão social da sustentabilidade se destaca através da repercussão das decisões políticas relativas à sociedade por elas afetadas.

Portanto, o respeito à dignidade da pessoa humana é essencial para que a sociedade permaneça em equilíbrio e viva condignamente.

Neste raciocínio, José Renato Nalini, conclui que a sustentabilidade importa em transformação social, propondo a integração, a unidade entre homem e a natureza, na origem e no destino comum significando um novo paradigma (NALINI, 2001, p.37).

A dimensão ética, assim como as demais dimensões da sustentabilidade, também envolve uma preocupação com o futuro, justamente no que tange a garantia da preservação das condições de vida daqueles outros seres humanos que virão futuramente.

Todo o processo de modernização das sociedades globalizadas como bem observa Apel, citado na obra de Manfredo Araújo de Oliveira, significou "um processo de automação cada vez mais acentuado da economia, que se tornou fim em si mesmo, e de predominância de uma liberdade provada, sem referências éticas e sem responsabilidade coletiva." (OLIVEIRA, 2010, p.16)

Portanto, atualmente o homem vivencia um problema ético, o que significa dizer que a ética precisa articular-se considerando todo o contexto histórico da sociedade, caracterizada pela interdependência das nações no contexto do mundo globalizado, afinal como bem coloca Manfredo Araújo de Oliveira: "Vivemos, portanto, hoje, a experiência fundamental de um "vácuo ético". (OLIVEIRA, 2010, p.16)

Neste contexto, o ser humano se torna insensível à desgraça da maioria da humanidade que vive em níveis de pobreza e miséria e se mostra indiferente a degradação dos ecossistemas, bem como a lenta extinção das espécies. Se esta postura persistir, nenhuma outra ética será capaz de existir a não ser aquela ética utilitarista, aquela do indivíduo isolado buscando sobreviver ou desfrutar sozinho dos benefícios da natureza. 
Por isso, hoje a dimensão ética da sustentabilidade chama a atenção para a necessidade da cooperação mútua entre os seres humanos, o que constitui a lógica objetiva do processo evolucionário e da vida, pois se torna preciso "pensar nas consequências da intervenção das ciências na ecoesfera e biosfera, bem como dos mercados globais, no nível de uma civilização planetária." (OLIVEIRA, 2010, p.20).

Sem sombras de dúvidas, o desenvolvimento global e qualitativo atrelado à proteção e preservação do meio ambiente, constitui um enorme desafio para as sociedades contemporâneas e, somente o estabelecimento de diretrizes sustentáveis capazes de garantir um futuro digno às novas gerações refletirá a dimensão ambiental da sustentabilidade.

Com o objetivo de aplicar práticas sustentáveis para o estabelecimento de regras para o uso racional dos meios naturais pelo homem, sem que isto represente a destruição da natureza.

Contudo, importante destacar que a dimensão ambiental da sustentabilidade não desconsidera os avanços tecnológicos, nem as benesses advindas com advento da globalização.

Neste contexto a natureza multidimensional da sustentabilidade constitui um novo paradigma de desenvolvimento que seja ambientalmente sustentável tanto no acesso quanto na utilização dos recursos naturais e na preservação da biodiversidade; socialmente sustentável no combate da pobreza e desigualdades sociais e no implemento da justiça e equidade social; politicamente sustentável na promoção e aprofundamento da democracia permitindo a todos, sem exceção, a participação nas decisões de ordem pública; juridicamente sustentável na manutenção e aperfeiçoamento dos mecanismos jurídicos que garantem e respeitem às normas de direitos fundamentais já atingidas pela sociedade; economicamente sustentável no combate ao desperdício primando pela utilização equilibrada dos recursos naturais e a produção de riqueza; e eticamente sustentável restando os objetivos econômicos subordinados às leis de funcionamento dos sistemas naturais e nos critérios de respeito à dignidade humana e de melhoria na qualidade de vida das pessoas.

Desta maneira, diante do cenário mundial que se apresenta, a sustentabilidade não pode apenas ser compreendida como um simples adjetivo ou um qualificativo de luxo irracionalmente incorporado a certas expressões ou propósitos discursivos, mas sim como um projeto estratégico de sobrevivência futura sedimentado na consciência crítica dos indivíduos acerca da finitude dos recursos naturais e de sua responsabilidade pela proteção e melhora das condições de vida da sociedade. 
Assim, verifica-se que sustentabilidade constitui um termo que está relacionado ao equilíbrio necessário entre a satisfação de necessidades e a viabilidade de existência das gerações futuras.

Portanto, é um conceito amplamente ligado à forma como as atitudes do presente influenciam o futuro. Por este motivo, da análise de seu conceito não pode furtar nenhuma das dimensões analisadas, já que estas não são excludentes, mas sim complementares e interdependentes entre si.

\title{
4. A SUSTENTABILIDADE JURÍDICA E OS DESAFIOS PARA O SEU ESTABELECIMENTO NA SOCIEDADE GLOBALIZADA
}

A globalização vivenciada nos dias atuais pela humanidade impôs a racionalidade econômica como forma de dominação da natureza e produziu a economização mundial implantada pelo sistema capitalista.

O atual paradigma da globalização é o mercado que livremente impõe as regras a serem seguidas, deixando de lado o protagonismo dos estados e das sociedades.

Os efeitos da globalização impuseram implicações consideráveis acerca das multidimensões da sustentabilidade, o que acentua a complexidade da sociedade global e institui novas demandas no âmbito jurídico, o que suscita a necessidade de uma rediscussão acerca do pensamento jurídico em vigor com a aproximação dos temas jurisdição e sustentabilidade.

A este respeito muito bem ilustra os dizeres de Ângela Araújo Espíndola:

\begin{abstract}
A jurisdição tradicional, liberal-individualista, voltada para a resolução de conflitos individuais e sob uma perspectiva essencialmente repressiva e reparadora, é ineficaz ante essa emergência de novos direitos e novas demandas. É preciso refundar a jurisdição e o processo. Para que seja possível responder às demandas contemporâneas desta sociedade complexa. (ESPINDOLA, 2013, p.64)
\end{abstract}

Surge, pois, a necessidade de novas respostas jurídicas, dada a "judicialização" das relações sociais, especialmente quando a complexidade da relação entre o homem e o meio ambiente se impõe no cenário social.

Compete ao Direito captar as realidades sociais e promover a solução dos conflitos modernos oriundos do sistema capitalista, mitigando-os e os administrando; assegurando a paz social e a realização do bem comum. 
Desta maneira, a percepção do direito ambiental como um direito de sustentabilidade fortalece o entendimento a respeito da ponderação dos direitos postulados no texto constitucional, posto que a demanda ambiental evidencia o choque entre a atividade humana e o meio ambiente sadio.

Neste sentido, a tutela judicial para a resolução e pacificação dos conflitos que envolvem questões ambientais, deve se afastar da ideia convencional do embate entre homem contra natureza, e defender a sustentabilidade da atividade do homem com o meio em que vive.

Diante desta compreensão, verifica-se que o direito ambiental colocado em juízo não serve apenas à aplicação de regras de preservação da natureza, mas sim a análise do Princípio da Sustentabilidade diante do caso real apresentado.

Esta realidade, na visão de GUSTIN (2006, p.08), traz à tona uma das principais preocupações jurídicas da contemporaneidade: a necessária interdisciplinaridade entre os ramos do Direito.

A realidade complexa e os conflitos surgidos na sociedade contemporânea exigem uma visão e atenção especial existindo a necessidade de uma análise jurídica interligada e coordenada com disciplinas conexas.

Esta situação é evidenciada, principalmente, quando se faz necessária a aplicação do Princípio da Sustentabilidade como suporte fático ao caso concreto.

Por isso, relevante se faz a necessidade do ordenamento jurídico ser analisado como uma unidade complexa de comunicação normativa, sob pena da perda de efetividade de todas as dimensões da sustentabilidade, pois a visão segmentada de cada ramo do Direito pode desenvolver tratamento jurídico parcial, por justamente se basear na regulamentação de relações específicas do Direito.

Desta maneira, a análise de questões relativas ao desenvolvimento sustentável não pode apenas se pautar no Direito Ambiental.

Por esta razão, o Princípio da Sustentabilidade reclama a análise de outros aspectos que vão além dos conflitos ambientais envolvendo a discussão de questões sociais, econômicas, políticas, jurídicas e éticas, pois constituem dimensões da sustentabilidade, e, como já sustentamos anteriormente, devem ser tratadas em sincronia, posto que tais dimensões não são excludentes, mas sim interdependentes e complementares entre si.

Corroborando este raciocínio, Fernanda de Salles Cavedon e Ricardo Stanziola Vieira, asseveram que uma utilização ideal da sustentabilidade deve prezar por uma análise e 
interpretação integrada dos direitos por ela engendrados que, reafirme-se, não podem ser adequadamente implementados de forma isolada. (CAVEDON; VIEIRA, 2008, p.173)

O tratamento interdisciplinar dos ramos do Direito propicia racionalmente objetivos por vezes distintos, que áreas específicas do Direito buscam.

Esta visão ampliada e coordenada do Direito permite uma reconstrução da principiologia dos segmentos específicos de cada ramo do Direito e oferece uma transformação nas bases do pensamento jurídico dominante imposto aos tradicionais segmentos jurídicos, que por sua vez, passam a ser analisados e percebidos como instrumentos de conexão e interpretação interligados entre si para a realização coerente, coesa, harmônica da jurisdição aplicada aos casos concretos que chegam ao Poder Judiciário, neutralizando a atual dogmática jurídica no tocante a resolução de questões complexas como a sustentabilidade.

\section{CONSIDERAÇÕES FINAIS}

O desenvolvimento global e qualitativo atrelado à preservação e proteção efetiva do meio ambiente atualmente representa um dos grandes desafios para as sociedades contemporâneas.

A sustentabilidade surge como o moderno paradoxo de transição pragmática, não podendo, por este motivo, ser apenas utilizada para qualificar um modelo de desenvolvimento e sua compreensão deve levar em consideração todas as dimensões, já que não representa uma construção unidimensional e isolada.

O estabelecimento de diretrizes sustentáveis é uma das principais tarefas destinadas ao Direito que sofre impactos da realidade complexa e os conflitos surgidos na sociedade moderna e, que urgem de uma análise jurídica integrada e coordenada com disciplinas conexas, pois surge a necessidade de novas respostas jurídicas dada a "judicialização" das relações sociais, especialmente quando a complexidade da relação entre o homem e o meio ambiente se impõe no cenário social.

Nesse contexto, a reformulação do pensamento jurídico e a quebra da atual dogmática jurídica no tratamento de questões complexas, como a sustentabilidade, se faz presente, posto que o ordenamento jurídico deve ser analisado como uma unidade complexa de comunicação normativa, sob pena da perda de efetividade de todas as dimensões da sustentabilidade, afinal 
a visão segmentada de cada ramo do Direito pode desenvolver tratamento jurídico parcial por se basear somente na regulamentação de relações específicas de Direito.

Deste modo, a análise de questões relativas à sustentabilidade e ao desenvolvimento sustentável não pode apenas estar baseada no Direito Ambiental; há a necessidade de que a análise de tais questões seja feita a partir de outros aspectos que vão além dos conflitos ambientais, pressupondo a discussão dos aspectos sociais, econômicos, políticos, jurídicos e éticos, posto que uma utilização ideal da sustentabilidade deve prezar por uma análise e interpretação integrada dos direitos por ela engendrados.

Desta forma, a sociedade global apresenta relevantes desafios para a aplicabilidade da jurisdição vez que demanda uma nova interpretação jurídica e por revelar as limitações da dogmática jurídica tradicional e do conhecimento isolado ou pertencente a um único ramo do Direito.

\section{REFERÊNCIAS}

BRASIL. Constituição da República Federativa do Brasil de 1988. Disponível em: < http://www.planalto.gov.br/ccivil_03/Constituicao/Constituicao.htm>.

CAVERNON, Fernanda de Salles, VIEIRA, Ricardo Stanziola. Socialismo e justiça ambiental como novas perspectivas para o direito ambiental: contribuições para a construção de um "direito da sustentabilidade". In: Revista Brasileira de Direito Ambiental. São Paulo: Fiúza, ano 4. v. 13, jan. barra mar. 2008.

ESPÍNDOLA, Ângela Araújo da Silveira. A refundação da jurisdição e as multidimensões da sustentabilidade. 2013.

FREITAS, Juarez. Sustentabilidade direito ao futuro. 2a ed. Belo Horizonte. Fórum. 2012.

GUIMARÃES, Roberto Pereira. Desenvolvimento sustentável: da retórica à formulação de políticas públicas. In: BECKER, Bertha K., MIRANDA, Mariana (orgs.). A geografia política do desenvolvimento sustentável. Rio de Janeiro: UFRJ, 1997.

GUSTIN, Miracy Barbosa de Sousa; DIAS, Maria Tereza Fonseca. (Re) pensando a pesquisa jurídica: teoria e prática. $2^{\text {a }}$ ed. Belo Horizonte: Del Rey, 2006.

LEFF, Henrique. Saber Ambiental: sustentabilidade, racionalidade, complexidade, poder. Tradução de Lúcia Mathilde Endlich Orth, Petrópolis, Rio de Janeiro: Vozes, 2001.

NALINE, José Renato. Ética Ambiental. Campinas, SP: Milenninum Editora, 2001.

OLIVEIRA, Manfredo Araújo de. Ética, direito e democracia. São Paulo: Paulus, Coleção Ethos, 2010. 
SACHS, Ignacy. Estratégias de transição para o século XXI. In: MENDES, Armando Dias; BURSZTYN, Marcel. Para pensar o desenvolvimento sustentável. $2^{a}$ ed. São Paulo: Brasiliense, 1994.

SANTOS, Boaventura de Souza. Pela mão de Alice: o social e o político na pós-modernidade. São Paulo. SP: Cortez, 2001.

SEM, Amartya. Desenvolvimento como liberdade. São Paulo, São Paulo: Companhia das Letras, 2000.

VEIGA, José Eli da. Desenvolvimento sustentável: O desafio do século XXI. Rio de Janeiro: Garamond, 2005. 